Article

\title{
Assessment of Human Outdoor Thermal Comfort in a Palm Grove during the Date Palm Phenological Cycle
}

\author{
Mohamed Elhadi Matallah 1,2,3 ${ }^{(D)}$, Hicham Fawzi Arrar ${ }^{2,4}$, Mohammed Faci ${ }^{5}\left(\mathbb{D}\right.$, Waqas Ahmed Mahar ${ }^{2,6,7}(\mathbb{D}$, \\ Fatima Zahra Ben Ratmia ${ }^{3}$ and Shady Attia ${ }^{2, *}$ D
}

1 Laboratory of Design and Modeling of Architectural and Urban Forms and Ambiances (LACOMOFA), Department of Architecture, University of Biskra, Biskra 07000, Algeria; elhadi.matallah@univ-biskra.dz

2 Sustainable Building Design (SBD) Lab, Department of Urban \& Environmental Engineering (UEE), Faculty of Applied Sciences, Université de Liège, 4000 Liège, Belgium; arrar.hicham@etu.univ-blida.dz (H.F.A.); architectwaqas@hotmail.com (W.A.M.)

3 Department of Architecture, University of Biskra, Biskra 07000, Algeria; fatimazahra.benratmia@univ-biskra.dz

4 ETAP Laboratory, Architecture and Urban Planning Institute, University of Blida, Blida 09000, Algeria

5 Center for Scientific and Technical Research on Arid Regions (CRSTRA), Biskra 07000, Algeria; fm_alg@yahoo.fr

6 Department of Architecture, Balochistan University of Information Technology, Engineering and Management Sciences (BUITEMS), Quetta 87300, Pakistan

7 Department of Architecture, CECOS University of Information Technology and Emerging Sciences, Peshawar 25000, Pakistan

* Correspondence: shady.attia@uliege.be

check for updates

Citation: Matallah, M.E.; Arrar, H.F.; Faci, M.; Mahar, W.A.; Ben Ratmia,

F.Z.; Attia, S. Assessment of Human Outdoor Thermal Comfort in a Palm Grove during the Date Palm Phenological Cycle. Atmosphere 2022, 13, 379. https://doi.org/10.3390/ atmos13030379

Academic Editors: Dragan Milosevic, Britta Jänicke, Yuliya Dzyuban and Michael Allen

Received: 15 January 2022

Accepted: 22 February 2022

Published: 24 February 2022

Publisher's Note: MDPI stays neutral with regard to jurisdictional claims in published maps and institutional affiliations.

Copyright: (C) 2022 by the authors. Licensee MDPI, Basel, Switzerland. This article is an open access article distributed under the terms and conditions of the Creative Commons Attribution (CC BY) license (https:// creativecommons.org/licenses/by/ $4.0 /)$.

\begin{abstract}
Oasis settlements in Saharan lands present a particular model of life for rural individuals adaptation to environmental challenges. This study investigated human outdoor thermal comfort in a palm grove of the Tolga region, Algeria, during the phenological cycle of the date palm. Date palms are the primary economic source of the cultivators, who mainly live in houses inside the cultivated area. For this study, an area of 21 hectares with 220 palm trees was selected. The phenological cycle of the date palm was divided into three growth stages, including seasonal variations as well. The cycle covers a period of 8 months from March to November. Therefore, on-site monitoring of the microclimate was performed during March-November 2021. The climatic factors of air temperature and humidity were monitored at an interval of $10 \mathrm{~min}$. The discomfort index based on temperature ranges covering discomfort conditions was used. The results showed that the cultivators work under extreme temperatures for 5.5 months during the phenological cycle. The spring period was more comfortable, while slight to extreme discomfort was observed in the summer and fall seasons, especially between midday and 7 p.m. Temperatures below $25^{\circ} \mathrm{C}$ are comfortable for the cultivators; however, severe discomfort occurs at $30^{\circ} \mathrm{C}$ or above. Moreover, the humidity was not a dominant factor for discomfort. These findings can be helpful for architects and planners to devise solutions that can fulfil human comfort requirements and date palm cultivar conditions, specifically during extreme thermal situations.
\end{abstract}

Keywords: oasis settlement; arid climate; Phoenix dactylifera; climate change; field monitoring; discomfort index (DI)

\section{Introduction}

Several studies have compared oasis settlements to 'islands in the desert' and connected their agricultural fortune to the worldwide market economy. Oases in many Saharan locations are historically well known for cultivation of the palm tree Phoenix dactylifera [1], which remains the crucial component of oasis sustainability. The palm tree is considered the backbone of the oasis ecosystem and the agricultural character of the social livelihood of the oasis. Therefore, the built environment of Phoenix dactylifera clearly illustrates its 
strong integration into the traditional rural landscape and the attachment of the Indigenous people to the palm grove [2,3]. It is the element and the source of life of these human groups [4]. The palm grove has a double advantage: economically, it provides a marketable and exportable product, which easily finds a market abroad [5,6]. Furthermore, it has an ecologic benefit for the desert lands. It ensures a zone that reduces evapotranspiration, allows a mild microclimate, and creates the 'oasis effect' due to the shade provided by the vegetated area [7-10]. Many cultivators are strongly attached to their cultivations within the oasis settlements. They live inside their palm groves, making their houses inseparable from the oasis settlement patterns [5]. Moreover, they ensure the cultivation of fruit varieties of date palm and other crops by working throughout the year, specifically during the summer season.

On the other hand, the succession of heat waves during the last decades and for future years due to climate change and extreme weather conditions could significantly impact the vegetative growth of plants and the human thermal requirements inside these hostile lands [11,12]. As the principal harvest of oasis cultivation, the date palm fruit has a specific development period named the phenological cycle within the year [13], which permits average growth. Accordingly, cultivators work hard in this period to ensure the productivity of their palm groves as the primary economic source. However, the thermal working and living conditions significantly impact the inhabitants' quality of life and the quality of cultivation [14]. Thus, regular and reliable thermal thresholds for date palm development are higher than human thermal requirements, which can cause remarkable thermal stress to people over a long time period.

Algeria is one of the worldwide leaders in date palm cultivation. According to the Food and Agriculture Organization (FAO) statistics (FAOSTAT) datasets [15], in 2017, the total area occupied by productive date palms was 1,329,973 ha, with production of $8,166,014$ tons, which gives a yield of $6140 \mathrm{~kg} / \mathrm{ha}$. Therefore, Algeria produced 1,058,559 tons of dates, with a higher yield than the global average $(6313.6 \mathrm{~kg} / \mathrm{ha})$ [16].

This study aimed to evaluate the cultivators' thermal comfort within the palm grove in the Tolga oasis territory in southern Algeria [17]. It further assessed human thermal requirements to clarify the levels of impact of the palm grove during date palm growth, and how the palm tree could be helpful or not for ensuring a favourable environment under the weather conditions of the Indigenous oasis settlements. Despite numerous studies about the influence of extreme weather patterns on the phenological cycle of the date palm [18-20], none of the previous research in Algeria, has focused on the human thermal requirements within the palm groves during date palm development, although it is a serious subject in terms of people's health, liveability, and agricultural productivity.

Therefore, this study aimed to evaluate the outdoor thermal comfort of a large social group in southern Algeria. More specifically, the following questions were answered:

- What is the impact of palm groves on human thermal requirements?

- Is the palm tree a suitable tool for thermal mitigation within Saharan cities?

The study aimed to assess the outdoor thermal comfort inside a palm grove during the phenological cycle of the date palm considered to be the most dynamic period. The article presents the background of the study and an introduction to the study context, and highlights the aim, objectives, and outcomes of this study. It further focuses on the thermal comfort evaluation criteria, reference case selection, field monitoring, and thermal comfort calculations.

The assessment of outdoor thermal comfort was carried out to pay particular attention to the weather patterns and outdoor thermal comfort in arid Algerian lands. Levels of heat stress were analysed, and the results were used to explore the real thermal sensation of the oasis settlement. Finally, recommendations for future work are outlined.

\section{Methodology}

The research methodology focuses on the assessment of human thermal stress inside a palm grove during the phenological cycle of the palm tree Phoenix dactylifera. Furthermore, 
the study demonstrated the impact of thermal requirements relevant to the date palm's growth stages on the thermal heat stress of the inhabitants (cultivators) throughout the palm groves in Tolga territory.

Accordingly, the target objective was to evaluate the outdoor thermal conditions of the cultivators inside their cultivation fields (the palm grove) and housing areas during the date palm growth cycle. The oasis livelihood depends strongly on the relationships among people, housing, and palm grove areas.

The following sections describe in depth the steps undertaken through the current study. Figure 1 illustrates the conceptual study framework, mentioning the steps taken and the process followed in the present study.

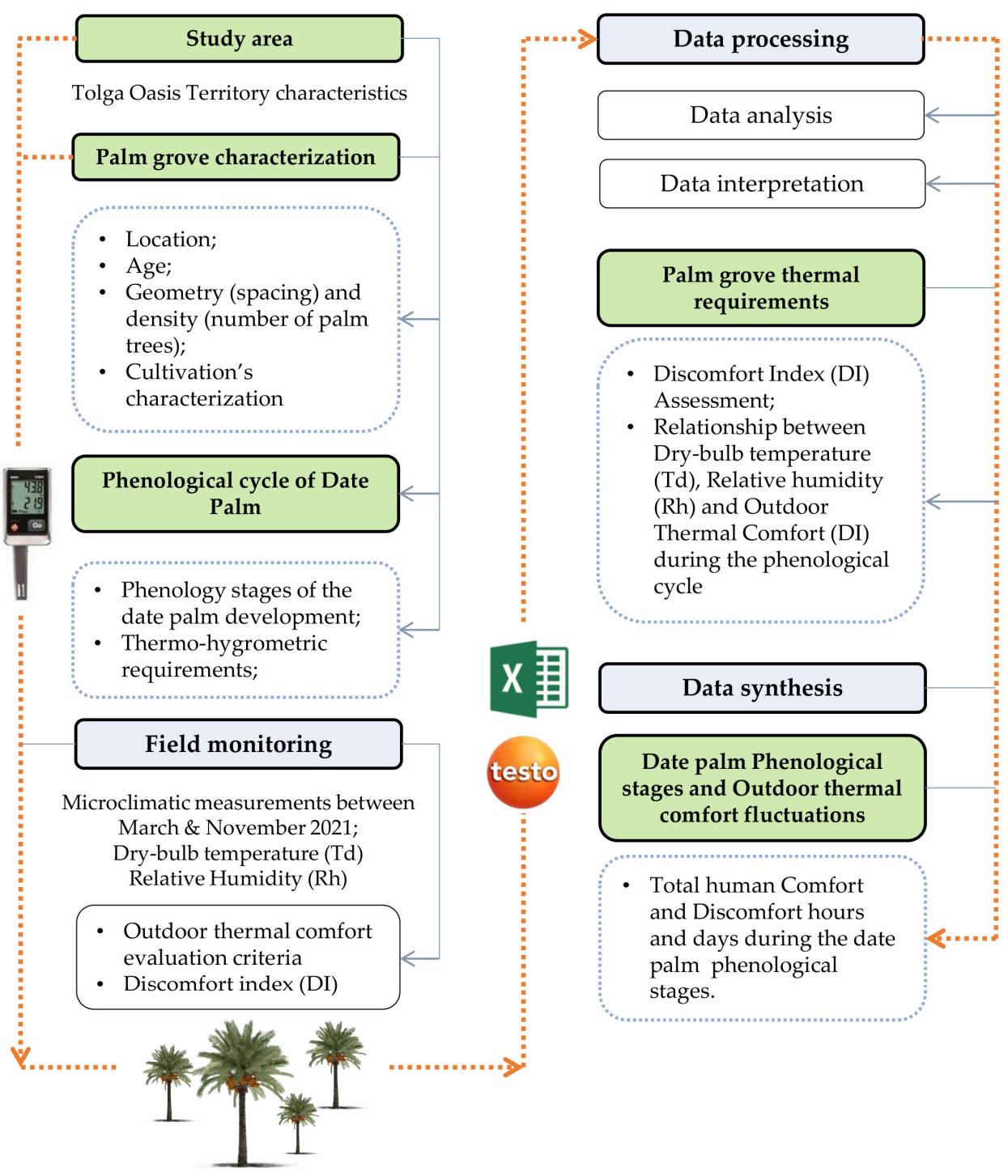

Figure 1. The study's conceptual framework.

\subsection{Study Area}

Tolga oasis territory is located in the Ziban region in the southeast of Algeria, behind the Saharan Atlas Mountain range, which is considered as natural barrier between the north and the south, and includes all the area at the foot of the Atlas range towards the large desert, and is endowed with different Saharan landscapes [5,6]. Named the gateway to the desert' due to its location at the beginning of the Sahara Desert, the Ziban region plays a role in encounters, exchange, and transition between the north and south of Algeria [4]. 
The Tolga oasis territory covers an area of $1590.50 \mathrm{~km}^{2}$ and is at a distance of $400 \mathrm{~km}$ southeast of the capital (Algiers), located at a latitude between $34^{\circ} 38^{\prime}$ and $35^{\circ} 5^{\prime}$ north and a longitude between $4^{\circ} 56^{\prime}$ and $5^{\circ} 35^{\prime}$ east (Figure 2). The Ziban region's climate is arid. According to the National Meteorological Office (NMO), the region is known for very high temperatures. Between 1998 and 2016, the studied area registered a yearly average temperature of $22{ }^{\circ} \mathrm{C}$ and a yearly maximum of $43^{\circ} \mathrm{C}$ (Figure 3) [21]. Furthermore, during the last 30 years the yearly average of heating degree-days (HDD) was estimated to be about 218, and the average of cooling degree-days (CDD) was 1780. On the other hand, Tolga oasis territory is characterized by deficient rainfall, with an average annual accumulation below $126 \mathrm{~mm}$ from 1995 to 2017 [22]. The rainfall is irregular and can be torrential. Therefore, the region experiences an extended dry phase, which is sometimes spread over the whole year [23].

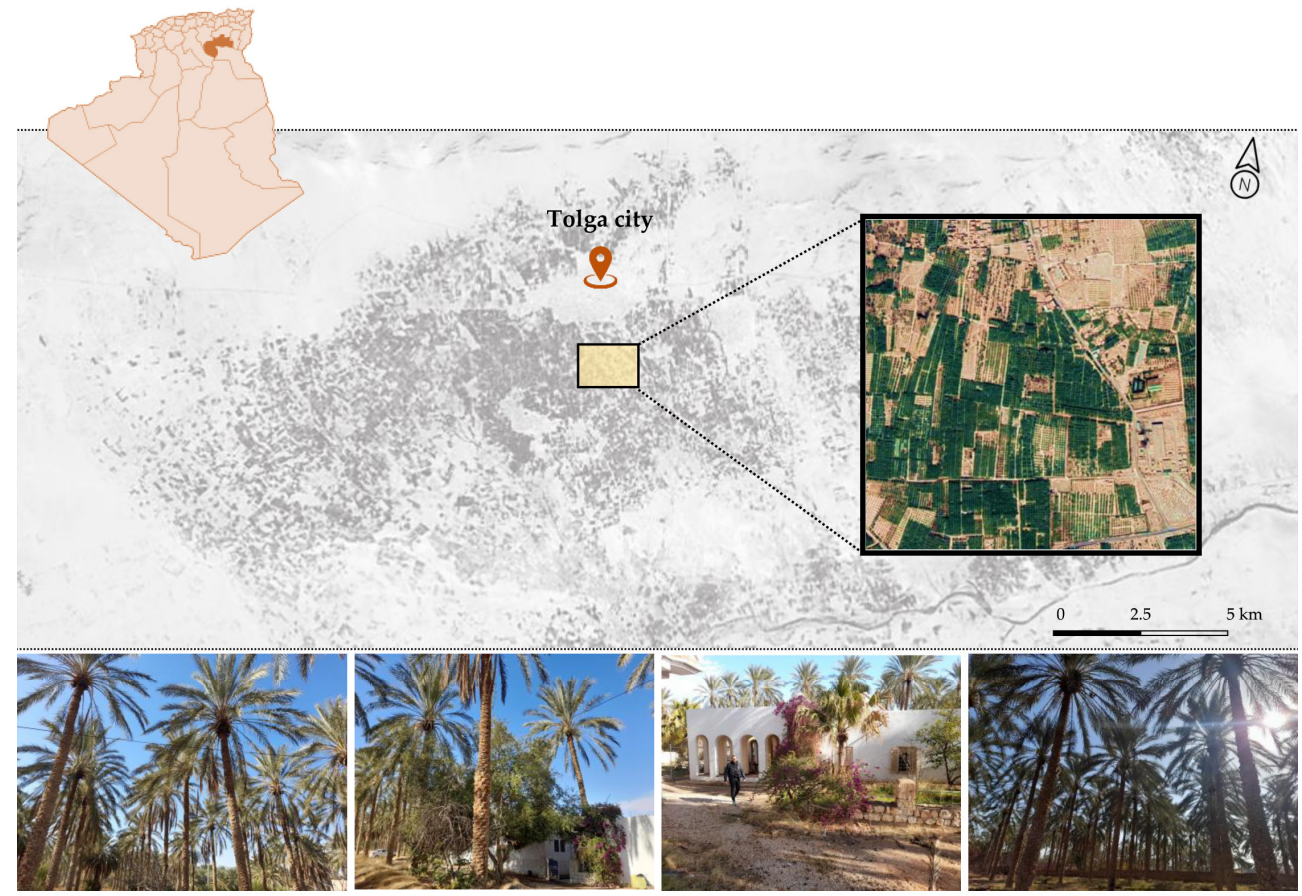

Figure 2. Location of the studied palm grove in the Tolga oasis territory.

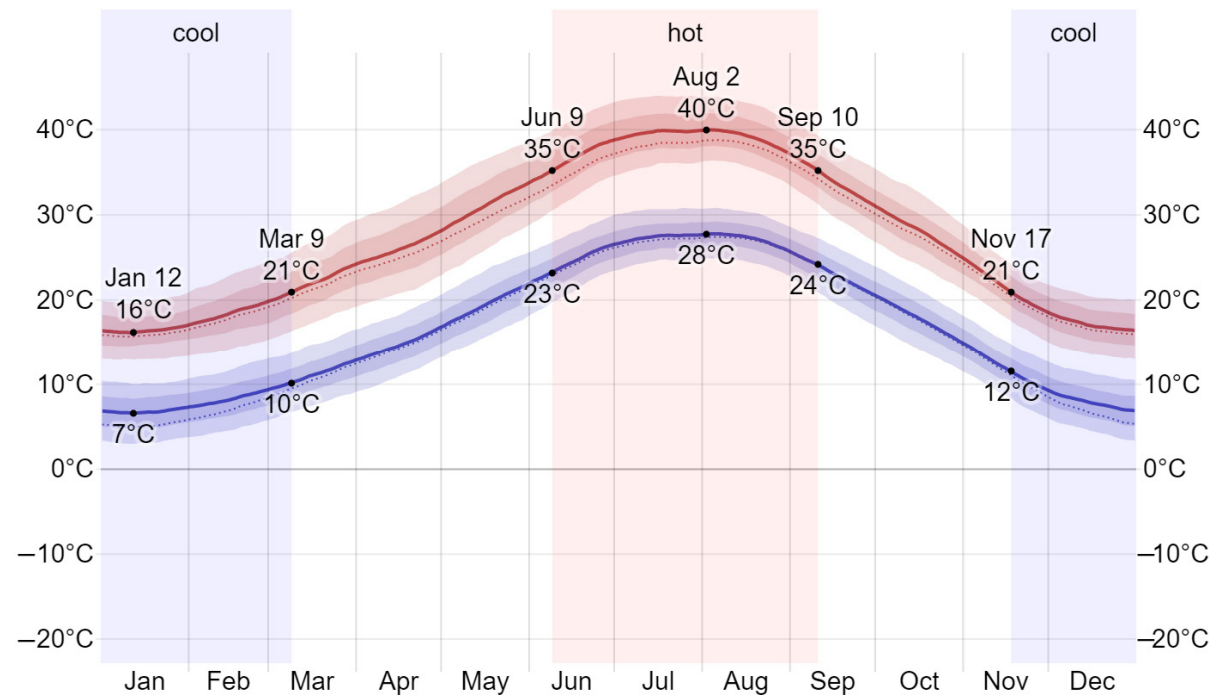

Figure 3. Monthly average outdoor temperatures in Algeria's Tolga oasis territory, between January 1998 and December 2016. 
Currently, the Tolga oasis territory counts more than 1,008,000 productive palm trees, of which the Deglet Nour variety has reached $80 \%$ of the total date palm heritage of the region.

\subsection{Palm Grove Characteristics}

According to the literature, the selection of representative reference palm groves is mainly based on vegetation density, morphology, and the age of palm trees. The selected area must also be a productive cultivation field and not abandoned.

The investigation was conducted in a productive palm grove in the Tolga oasis territory in Biskra province that was created at the beginning of the 1960s, with an area of 21 hectares and around 220 palm trees dominated by the 'Deglet Nour' variety, spaced with $8 \mathrm{~m}$ between the palm trees and a height of $10 \mathrm{~m}$. The study area contains a few fruit trees (fig, pomegranate, and vine), for which the irrigation is by submersion and permanent maintenance (throughout the year). The density of vegetated areas is similar to other neighbouring palm groves characterized by the same palm trees, spacing, and disposition among the fields.

The cultivated surface covers around $98 \%$ of the total area, whereas the cultivator's house represented $2 \%$ and is surrounded by palm trees (Figure 4 ). The date palm cultivar needs daily monitoring, especially during its phenological stages, to ensure productivity.

\section{- Tolga, Algeria \\ $134^{\circ} 43^{\prime} 00^{\prime \prime} \mathrm{N} ; 5^{\circ} 23^{\prime} 00^{\prime \prime} \mathrm{E}$}

220 palm trees / Implementation in 60's

$21,980 \mathrm{~m}^{2}$
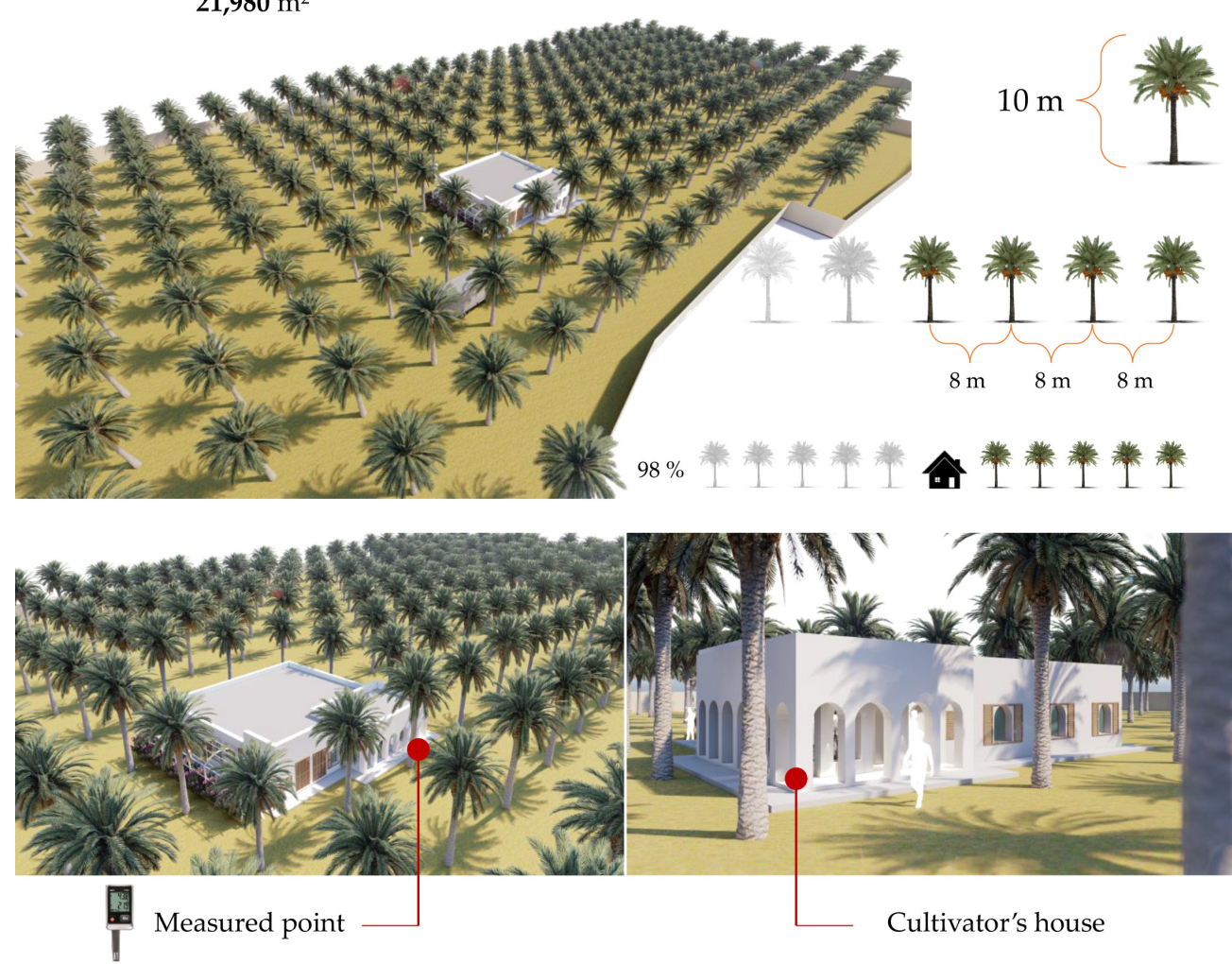

Figure 4. Implementation and characterization of the studied palm grove.

\subsection{Phenological Cycle of the Date Palm}

The date palm belongs to the Arecaceae (syn. Palmaceae) family, and the genus Phoenix contains 12 species. Dactylifera is the most important species in terms of commercial value and human food use [16]. Moreover, as a dioecious plant, male and female flowers are 
borne on two different palms, and many male and female cultivars have been successfully identified and cultivated.

Many experts such as Munier [1], and Zaid and De Wet [24] have described the significance of Phoenix dactylifera.

On the other hand, phenology involves the study of the occurrence of periodic annual events in the living world, determined by seasonal variations in climate [11]. Therefore, it is essential to consider climatic influences on phenology [13].

The phenological cycle of Phoenix dactylifera is divided into three growth stages: (i) the appearance and the opening of the spathes, (ii) the development of the fruits, and (iii) the maturity of the fruits and the vegetative rest period.

The cycle starts with the pollination stage in spring (March to May) and varies in time depending on the precocity of the varieties and the season's climatic conditions. The fruiting stage begins at fruit setting and ends at the mature date ripening stage. Therefore, the fruiting period varies from 120 to 200 days, depending on the region and cultivar [25]. Deglet Nour is considered a late-maturing variety (taking longer to ripen) [13]. Generally, the fruit of the cultivar Deglet Nour matures in October (Figure 5).

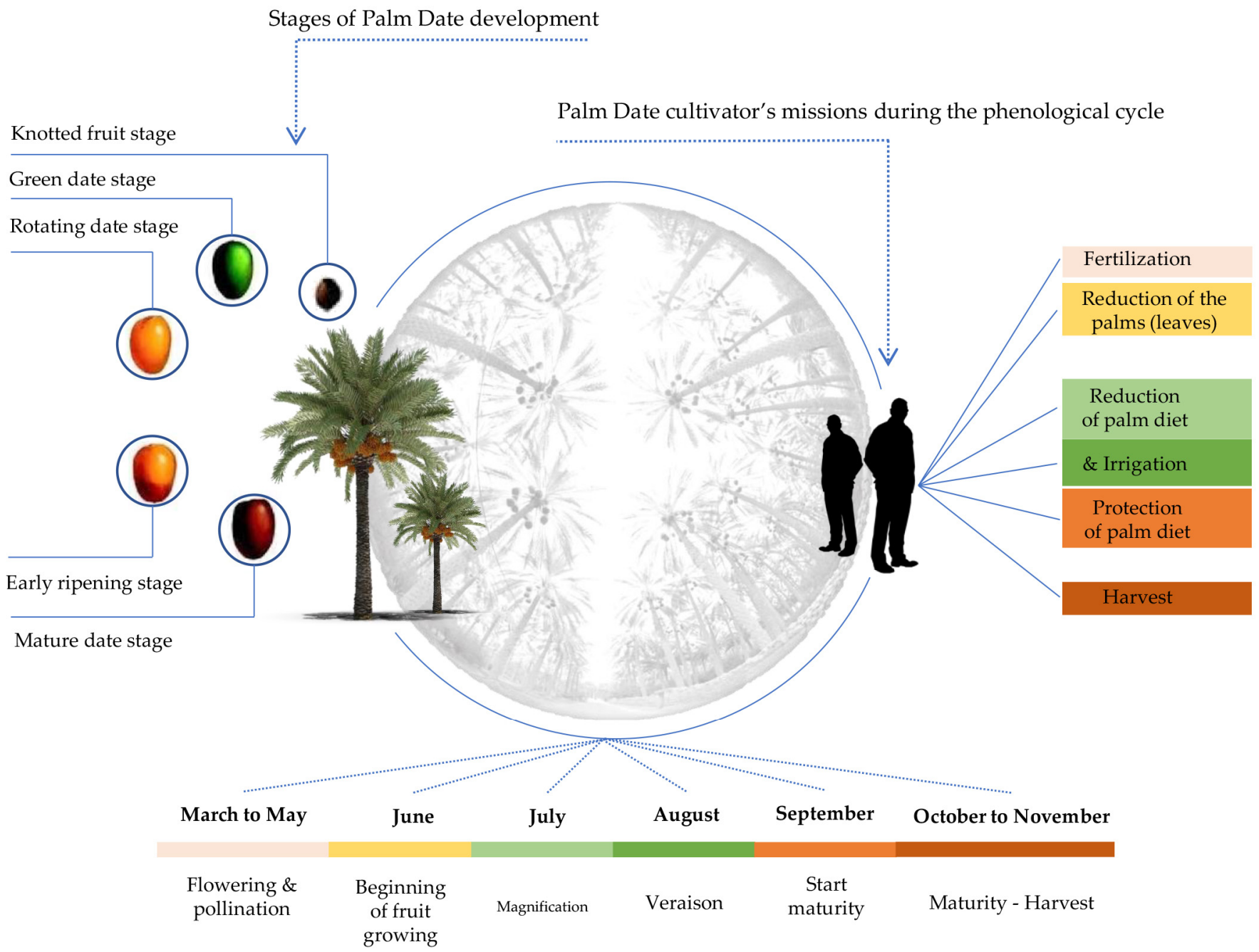

Figure 5. Phenological stages of the date palm and their agricultural processes.

In particular, the normal development of Phoenix dactylifera requires extreme weather conditions, specifically in summer, with very low humidity rates and rainfall quantities. Moreover, palm trees need a sound irrigation system during the year (Table 1). 
Table 1. Principal environmental requirements of the palm tree.

\begin{tabular}{cc}
\hline Climate Adaptation & Climatic and Cultivation Conditions \\
\hline Favourable vegetation growth boundaries & $\begin{array}{c}{ }^{\circ} \mathrm{C} \text { to } 45^{\circ} \mathrm{C} \text { (dry temperature) } \\
20 \% \text { to } 70 \% \text { (relative humidity) }\end{array}$ \\
\hline Maximum temperature intensity of date palm & $38^{\circ} \mathrm{C}$ \\
\hline Frost sensitivity & $\begin{array}{c}\text { Palm tips: }-6{ }^{\circ} \mathrm{C} \\
\text { All the palms: }-9{ }^{\circ} \mathrm{C}\end{array}$ \\
\hline Tolerated drought duration & For several years, but with reduced growth and \\
production
\end{tabular}

\subsection{Field Monitoring}

The study is based on hourly microclimatic measurements in the site between 25 March and 25 November 2021, which is representative of the phenological cycle period in Algeria.

The monitoring of microclimatic parameters was carried out by using a Testo $175 \mathrm{H} 1$ data logger [26] for measuring the dry-bulb temperature $(\mathrm{Td})$ and relative humidity $\left(\mathrm{R}_{\mathrm{H}}\right)$. Table 2 presents the details of the data logger. To manage the device's recorded datasets, we needed to set up a complementary tool 'Comfort Software Basic 5.0' [26], which is compatible with the instrument used.

Table 2. The monitoring instrument used for the study.

\begin{tabular}{cccccc}
\hline \multicolumn{5}{c}{ Meteorological Data Parameters } \\
\hline Variable & Device & Dimensions & Unit & Accuracy & Range \\
\hline Dry-bulb temperature $\left(\mathrm{T}_{\mathrm{d}}\right)$ & Testo $175 \mathrm{H} 1$ & $149 \times 53 \times$ & ${ }^{\circ} \mathrm{C}$ & $\pm 0.4{ }^{\circ} \mathrm{C}$ & -20 to $+55^{\circ} \mathrm{C}$ \\
\cline { 4 - 6 } & 05721754 & $27 \mathrm{~mm}$ & $\%$ & $\pm 1.0 \%$ & 0 to $100 \%$ \\
\hline
\end{tabular}

The data logger recorded 144 values per day, equivalent to one measurement per $10 \mathrm{~min}$. It was installed in the middle of the palm grove close to the cultivator's house, at the height of $2.10 \mathrm{~m}$ from the ground to avoid the soil reflectivity and water evaporation effects.

Recently, many studies have been focusing on fluctuations in air temperature and humidity rates related to climate change patterns and their impact on the phenological cycle $[12,18,20]$. Thus, climate changes can significantly modify the date palm stages by accelerating some development stages and reducing the cycle period.

During the phenological cycle, cultivators of date palm perform several operations to ensure good cultivation of their own crops. These missions are distributed among cultivators inside the palm groves and relate to the date palm development stages, including: (i) fertilization, (ii) reduction of palms (leaves) (cutting off the dry ones), (iii) reduction of palm dates (an operation to reduce excess date palm branches), (iv) irrigation, (v) protection of the palm dates, and (vi) harvest of the fruits.

It is, therefore, necessary to indicate that the number of cultivators during these missions differs depending on the cultivation area (the number of palm trees) and the phenological stage, and can be between 3 workers and more than 100 . 


\subsection{Outdoor Thermal Comfort Evaluation Criteria}

Lately, researchers have paid particular attention to thermal comfort in urban environments and its effect on inhabitants. Numerous studies have attempted to define thermal comfort conditions to determine the concept of thermal sensation in outdoor spaces. Thermal comfort is referred to as user satisfaction regarding the thermal environment [27]. It is essential to understand the microclimate's environmental characteristics to reveal their levels of impact on human thermal requirements and outdoor activities. For several years, researchers have focused on the development of evaluation indices that can assess human thermal comfort for different global climatic zones [28]. The thermal indices have mainly been developed on the basis of their application methods, which constitute three significant categories:

(i) Thermal indices based on humans' energy balance, representing the interaction among metabolic activities, clothing, and environmental parameters, and on people's thermal perceptions, such as the COMFA model [29], the index of thermal stress (ITS) [30], physiological equivalent temperature (PET) [31], predicted mean vote (PMV) [32], perceived temperature (PT) [33], and the universal thermal climate index (UTCI) [34];

(ii) Indices based on linear equations which define human comfort as an interaction of the thermal environment, focusing on the impact of air temperature and relative humidity but neglecting human behaviour, such as the apparent temperature (AT) [35], the discomfort index (DI) [36,37], the environmental stress index (ESI) [38], effective temperature (ET) [39], the heat index (HI) [40], and the relative strain index (RSI) [41];

(iii) Empirical indices, which are very close to linear equation indices, define human comfort for a specific climate and are defined as linear regressions based on field studies (onsite monitoring and surveys), such as the actual sensation vote (ASV) [42], thermal sensation (TS) [43], and the thermal sensation vote (TSV) [44].

On the basis of this literature review, we focused on the linear equation indices, specifically the 'discomfort index' at the micro-scale level, which was considered to be a favourable and applicable thermal index for our study purpose. It defines human beings' thermal dissatisfaction under certain climatic conditions, calculated on the basis of hourly climatic data such as dry-bulb air temperature $(\mathrm{Td})$ and relative humidity $\left(\mathrm{R}_{\mathrm{H}}\right)$. Moreover, the DI has largely been used in several studies within different climate zones such as the Mediterranean climate [45,46], humid subtropical climates [47,48] and arid climates [49-51], primarily seeking to assess people's discomfort thresholds during the summer season.

The discomfort index (DI) is based on an extensive series of microclimatic monitoring data $[36,37,50]$. It depends on the dry-bulb air temperature $(\mathrm{Td})$ and relative humidity $\left(\mathrm{R}_{\mathrm{H}}\right)$. Human discomfort increases as the DI increases.

The calculation of the discomfort index (DI) is based entirely on the drub-bulb temperature $(T d)$ and the relative humidity $\left(R_{H}\right)$ values, and is given as follows [37]:

$$
\mathrm{DI}=\mathrm{Td}-0.55\left(1-0.01 \mathrm{R}_{\mathrm{H}}\right) \times(\mathrm{Td}-14.5)
$$

where $\mathrm{Td}$ represents the average hourly value of the dry-bulb temperature $\left({ }^{\circ} \mathrm{C}\right)$ and $\mathrm{R}_{\mathrm{H}}$ is the average hourly value of the relative humidity (\%). The ranges and classifications of the DI values were given by Thom [37], as explained in Table 3.

Table 3. Discomfort index (DI) ranges [50].

\begin{tabular}{cc}
\hline DI $\left({ }^{\circ} \mathbf{C}\right)$ & Discomfort Conditions \\
\hline DI $<21$ & No discomfort \\
$21 \leq \mathrm{DI}<24$ & Less than $50 \%$ of people feel discomfort \\
$24 \leq \mathrm{DI}<27$ & More than $50 \%$ of people feel discomfort \\
$27 \leq \mathrm{DI}<29$ & Most people feel discomfort \\
$29 \leq \mathrm{DI}<32$ & Very strong discomfort \\
$\mathrm{DI} \geq 32$ & Medical emergency \\
\hline
\end{tabular}


As shown in Table 3, DI thermal stress zones start above the $21^{\circ} \mathrm{C}$ range, which represents the neutral or no discomfort zone. Above a DI of $21^{\circ} \mathrm{C}$, human thermal stress begins to be felt, and is strongly perceived at a DI of $27^{\circ} \mathrm{C}$ by a large number of people.

\section{Results}

In the following sections, we present the results of the outdoor thermal comfort assessment inside the palm grove as a crucial component of an oasis settlement, and we describe in detail the human thermal stress variations during each stage of the phenological cycle and their duration.

\subsection{Data Processing and Analysis}

Based on the dataset shown in Figure 6, it was found that between June and August, the air temperatures were remarkably constant at higher values during the daytime and night time hours, when the maximum was $\mathrm{Td} \max =46.3^{\circ} \mathrm{C}$ on 1 July at 3:00 p.m. Thus, the air temperature daily averages were above $30^{\circ} \mathrm{C}$ from 28 May to 20 September. On the other hand, the minimum air temperatures were recorded during the spring (March to May) and fall seasons (October to November), with $\mathrm{Td} \min =9.6{ }^{\circ} \mathrm{C}$ at 8:00 a.m. on 25 November. During the entire phenological cycle, the date palm activity air temperature threshold was suitable, with an average $\mathrm{Td}$ of $28.7^{\circ} \mathrm{C}$.

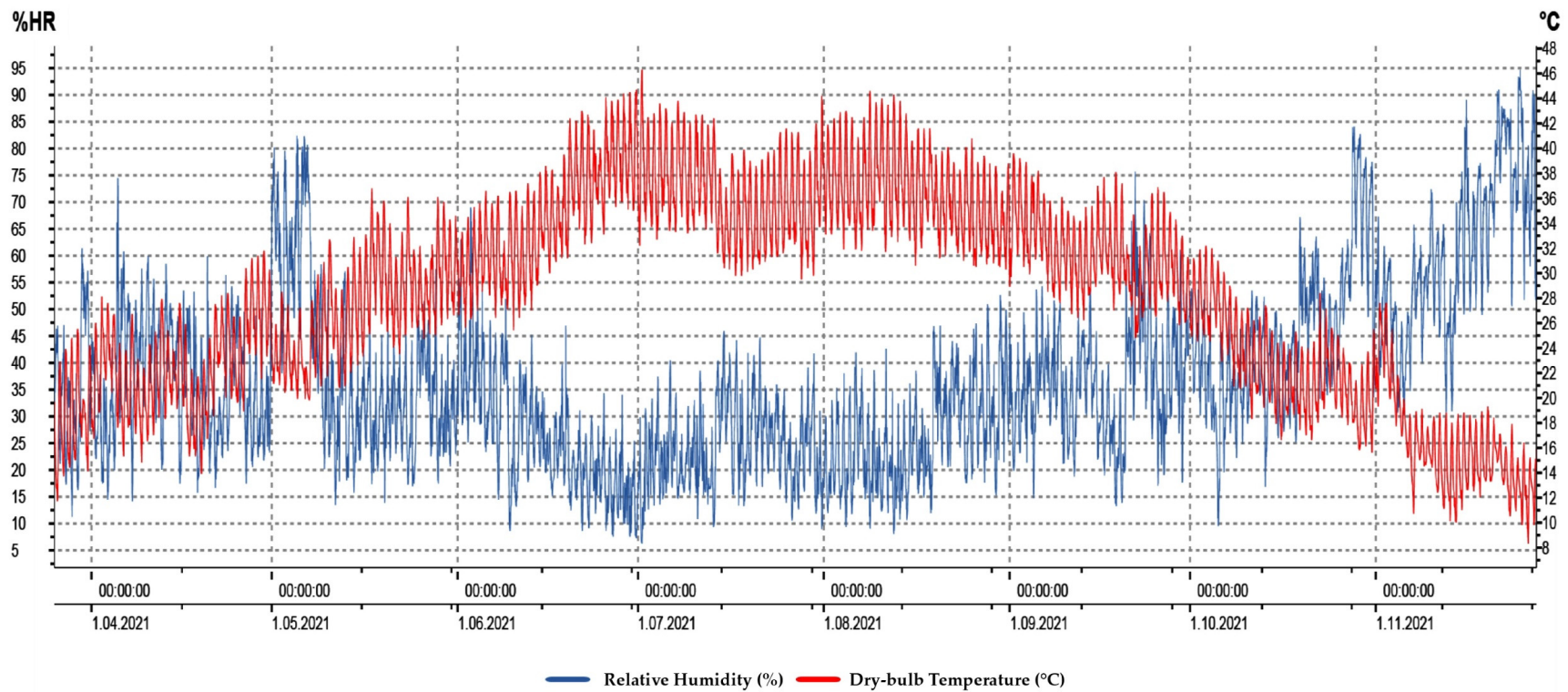

Figure 6. Dry-bulb temperature $(\mathrm{Td})$ and relative humidity $\left(\mathrm{R}_{\mathrm{H}}\right)$ variations between 25 March and 25 November 2021 inside the study site.

Relative humidity inside the palm grove reached its maximum on 5 May at 3:00 a.m. at $\mathrm{R}_{\mathrm{H} \text { max }}=82.4 \%$. It should be noted that maximums were recorded during rainy days in the first week of May 2021. The evapotranspiration inside the vegetated area was the principal factor of increasing humidity. However, the minimum value was $R_{H \text { min }}=6.20 \%$ at 3:00 p.m. on 1 July. Between 1 June and 31 August, which showed the lowest humidity values, the average was equal to $26.4 \%$, and several days were below $20 \%$. On the other hand, the total average during the phenological cycle was $\mathrm{R}_{\mathrm{H}}=37.0 \%$, a suitable range for date palm growth.

The recorded climatic thresholds inside the palm grove were generally in the normal ranges of date palm growth activity. Heat waves (above $42^{\circ} \mathrm{C}$ ) were temporarily observed in the last week of June, the first days of July, and the beginning of August. 


\subsection{Palm Grove Thermal Requirements}

During the phenological cycle, the relationship between the measured relative humidity $\left(R_{H}\right)$ and the human discomfort index (DI) was medium, with $R^{2}=0.5164$.

Despite the notable fluctuations in the humidity, Figure 7 shows the medium impact of the relative humidity on the human discomfort index throughout the palm grove field from March to November.

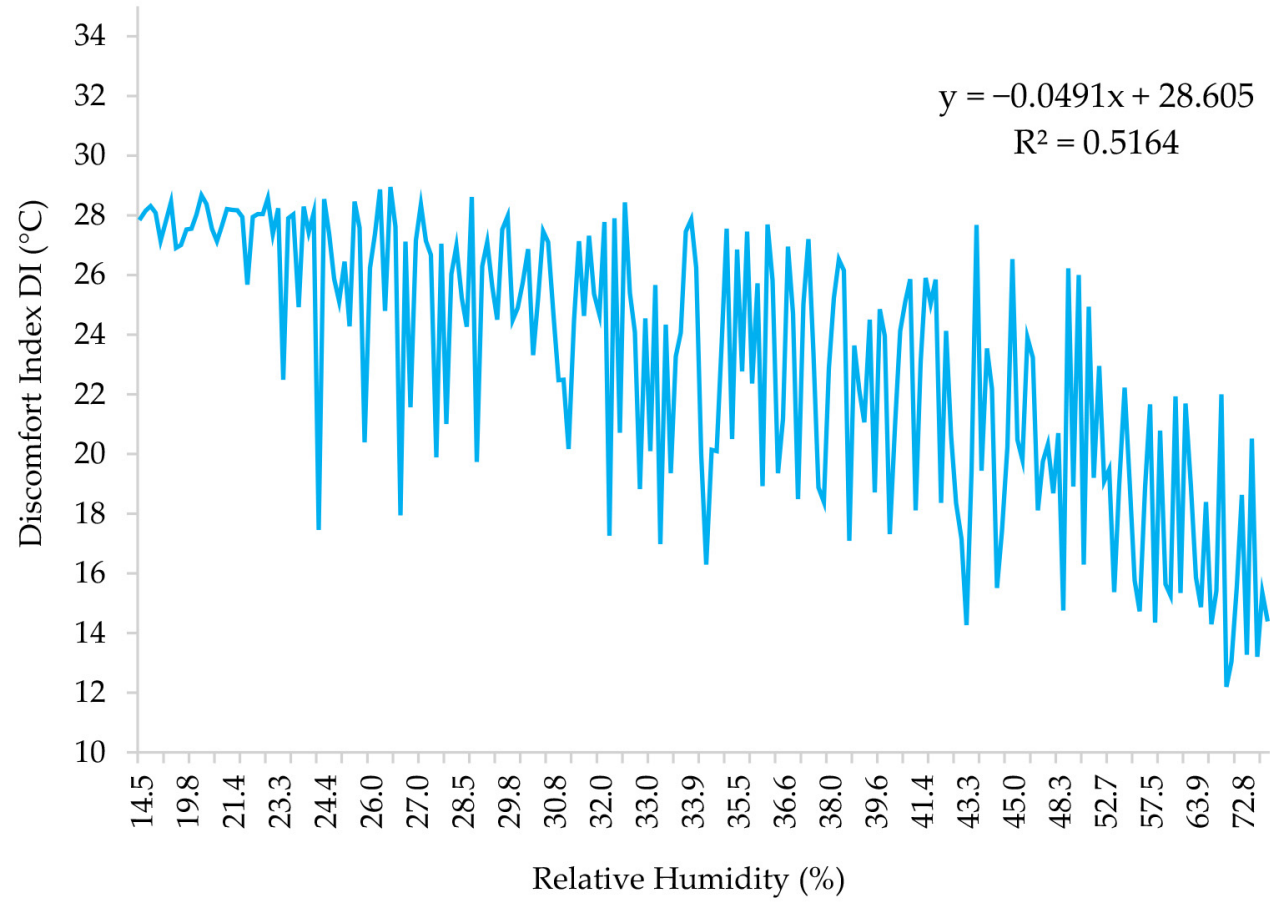

Figure 7. Relationship between relative humidity $\left(\mathrm{R}_{\mathrm{H}}\right)$ and the discomfort index (DI) during the phenological cycle at the study site.

The highest DI value was $\mathrm{DI}_{\max }=30.7^{\circ} \mathrm{C}$, assessed on 9 August at a relative humidity value of $R_{H}=18.1 \%$, which was not the minimum value during the total measurement period.

Contrary to relative humidity $\left(R_{H}\right)$, the observed relationship between the recorded dry-bulb temperatures (Td) and the evaluated discomfort index (DI) was very significant with $\mathrm{R}^{2}=0.9515$. Therefore, the obtained results confirmed that the discomfort index (DI) is most influenced by air temperature compared with relative humidity in arid regions.

As the curve shows in Figure 8, the dry-bulb temperature (Td) had a high impact on human thermal stress during the phenological stages of the palm grove. The DI values rose progressively depending on the increase in dry-bulb temperature, especially during the summer season (June, July, and August).

Therefore, the no thermal stress zone (neutral) during the phenological cycle was perceived below a dry-bulb temperature of $25^{\circ} \mathrm{C}$. On the other hand, above $25^{\circ} \mathrm{C}$, the thermal discomfort becomes higher, and becomes stronger as the air temperature increases.

Figure 9 summarizes the hourly thermal stress rates which could be felt by cultivators during the phenological cycle inside their palm groves. As shown, the neutral zone (no discomfort) had an average of $32 \%$ versus $68 \%$ thermal discomfort, which covered four thermal stress zones: $18 \%$ for moderate discomfort (less than $50 \%$ of people feel discomfort), $30 \%$ for medium discomfort (more than $50 \%$ of people feel discomfort), $17 \%$ for high discomfort, and 3\% for very strong discomfort. 


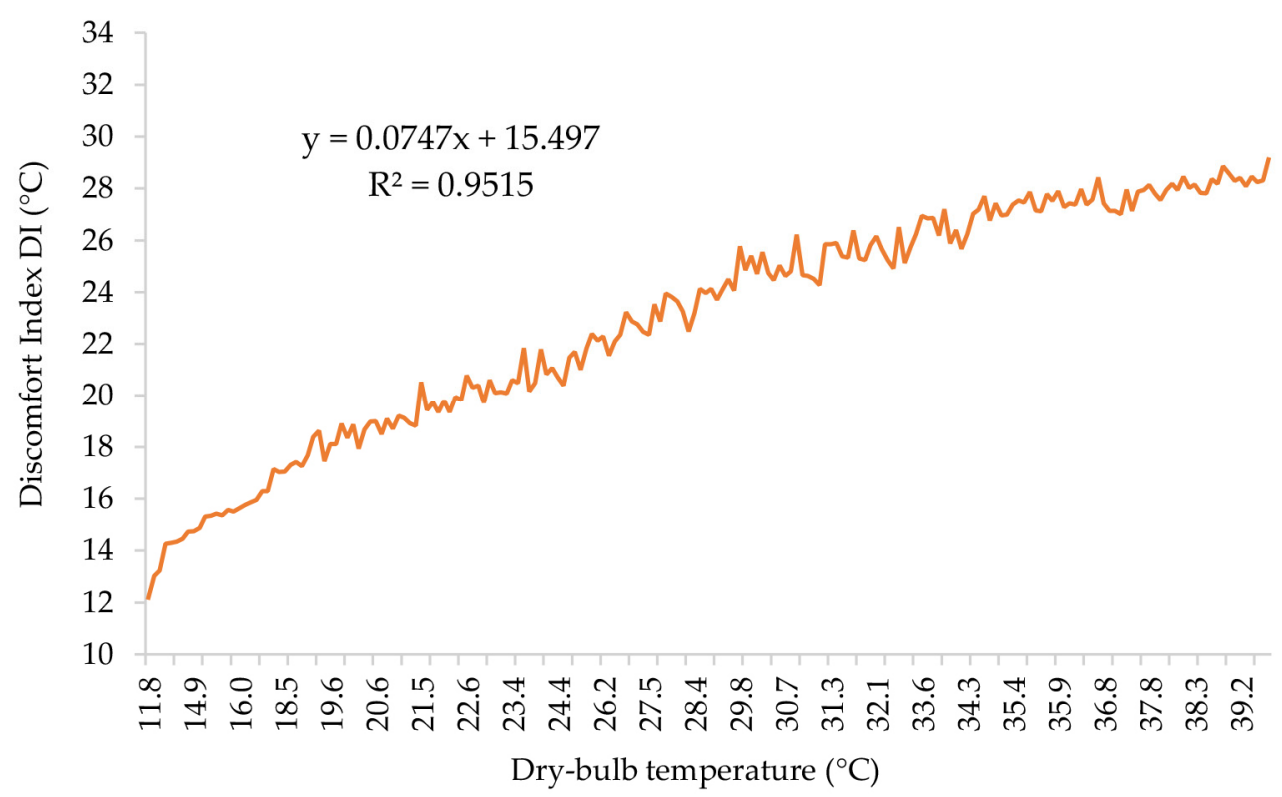

Figure 8. Relationship between dry-bulb temperature $(\mathrm{Td})$ and the discomfort index $(\mathrm{DI})$ during the phenological cycle at the study site.

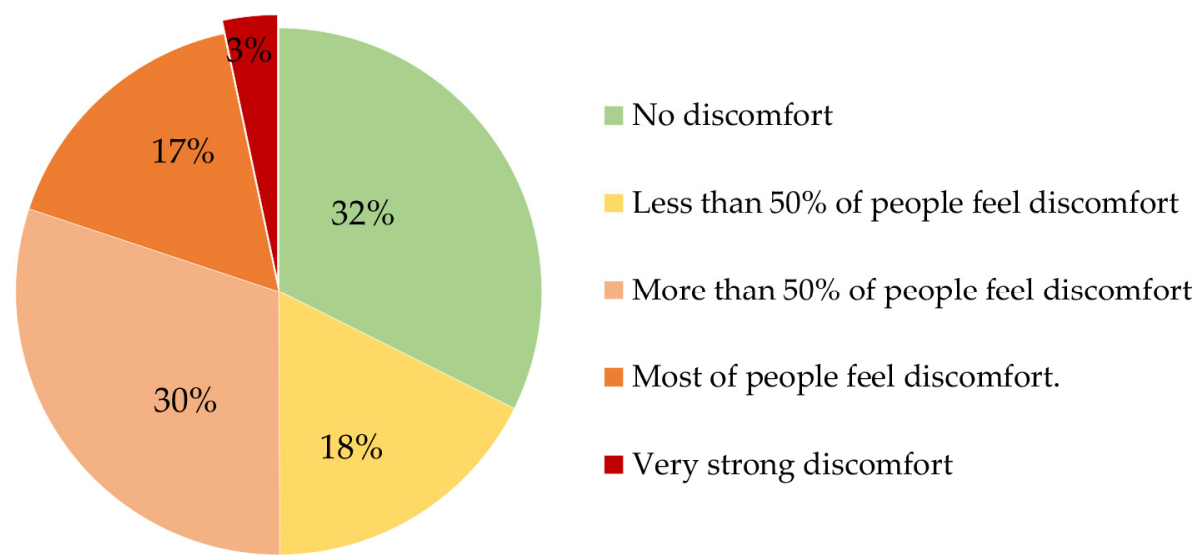

Figure 9. Hourly outdoor thermal comfort variation during the phenological cycle.

According to the results, the neutral zone was largely recorded during the spring season (from March to May) and all the night time hours. However, during the hottest days (summer season), the hours of feeling discomfort also covered the first daytime hours (before 6:00 a.m.), which is considered to be the cultivators' preferable starting time for work.

On the other hand, cultivators felt discomfort during the daytime hours of summer and fall seasons (from June to October). Medium, high, and very strong discomfort thermal zones were found between 10:00 a.m. and 7:00 p.m., considered to be the main working times inside the palm groves.

The feeling of extreme discomfort was significantly remarkable during the summer season between midday and 7:00 p.m., when overheating reduces most of the cultivators' tasks throughout their cultivated areas.

From the DI calculation, the night time hours (from 8:00 p.m. to 4:00 a.m.) were when lower temperatures were observed compared with the rest of the day in the phenological cycle, although the cultivation's tasks are very few at this time.

In terms of days, as shown in Figure 10, the total duration of the phenological cycle of the palm trees can reach 250 days, spreading from March to November. Furthermore, human thermal sensitivity is related to microclimatic conditions and thermal requirements 
inside the palm grove. The neutral zone (no discomfort) covers 82 days during March, April, October and November.

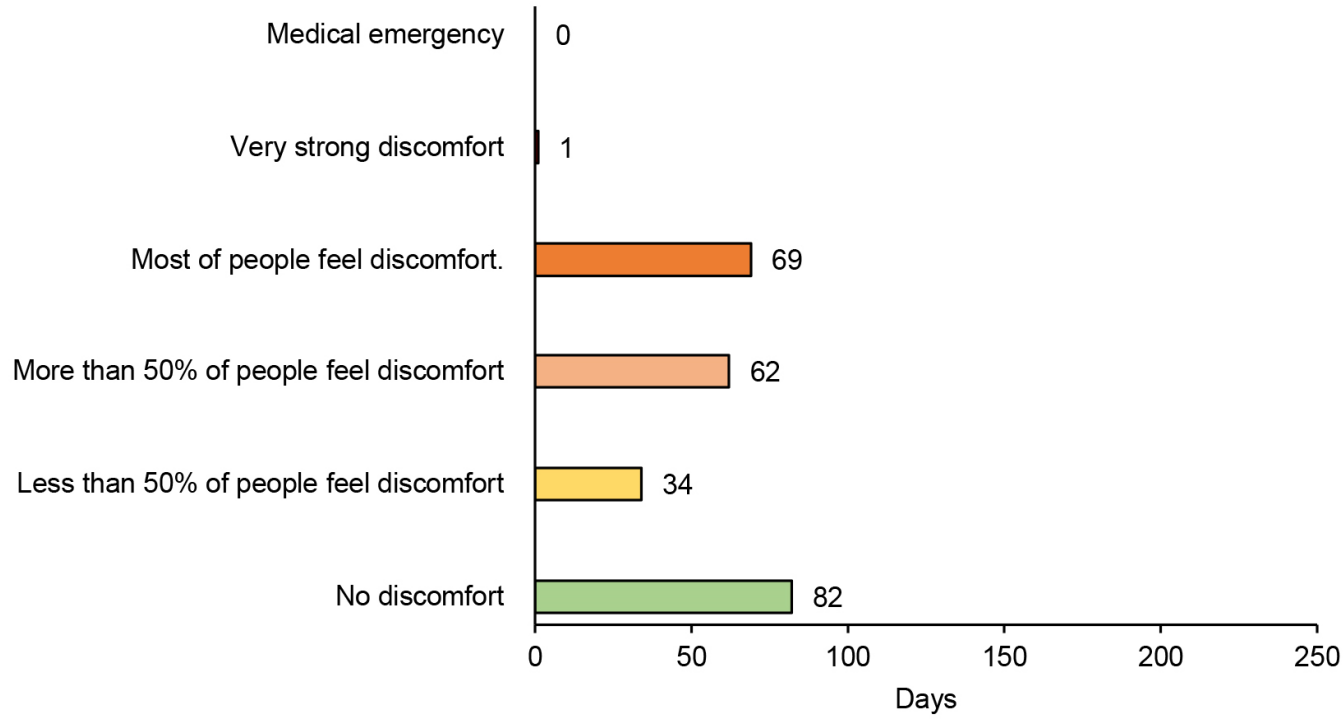

Figure 10. Number of human thermal stress days inside the palm grove during the phenological cycle.

Discomfort zones occupied 166 days, divided into four temporal thermal zones: 34 days of slight thermal stress (when less than $50 \%$ of people feel discomfort), mostly perceived during May, and 62 days of medium discomfort (more than $50 \%$ of people feel discomfort), occurred significantly in June and September. Moreover, 69 days of high discomfort and one day of very intense discomfort were estimated to occur between the last week of June and the first days of September.

During the 82 days of neutral thermal sensitivity, the average DI was $17.9^{\circ} \mathrm{C}$. On the other hand, on the 34 days, 62 days, and 69 days defined as the slight discomfort, medium discomfort, and high discomfort zones, the average DI was $22.5^{\circ} \mathrm{C}, 25.5^{\circ} \mathrm{C}$, and $27.8^{\circ} \mathrm{C}$, respectively.

Therefore, cultivators were carrying out their agricultural tasks during the phenological cycle, often under thermal discomfort conditions. In contrast, the no discomfort zone represented only $33 \%$ of the total duration, which totalled 248 days. The duration of thermal discomfort was increasing between June and September, representing $53.2 \%$ of the phenological cycle period.

As shown in Figure 11, reduction of the palms, reduction and protection of palm dates, and summer irrigation are the most challenging missions in terms of human thermal comfort during the phenological stages covering June, July, August, and September. Notably, all three tasks are carried out within DI ranges from $25^{\circ} \mathrm{C}$ to the $29^{\circ} \mathrm{C}$ threshold, which indicates very strong discomfort conditions.

According to the DI daily averages in Figure 12, during the period between 28 May and 30 September, the human thermal stress inside the palm grove was remarkably higher than other days. Additionally, from 18 June to 6 September, most people felt thermally discomfortable, with the peak day registered on 28 June with DI $=29.1^{\circ} \mathrm{C}$ with a very strong feeling of discomfort. 


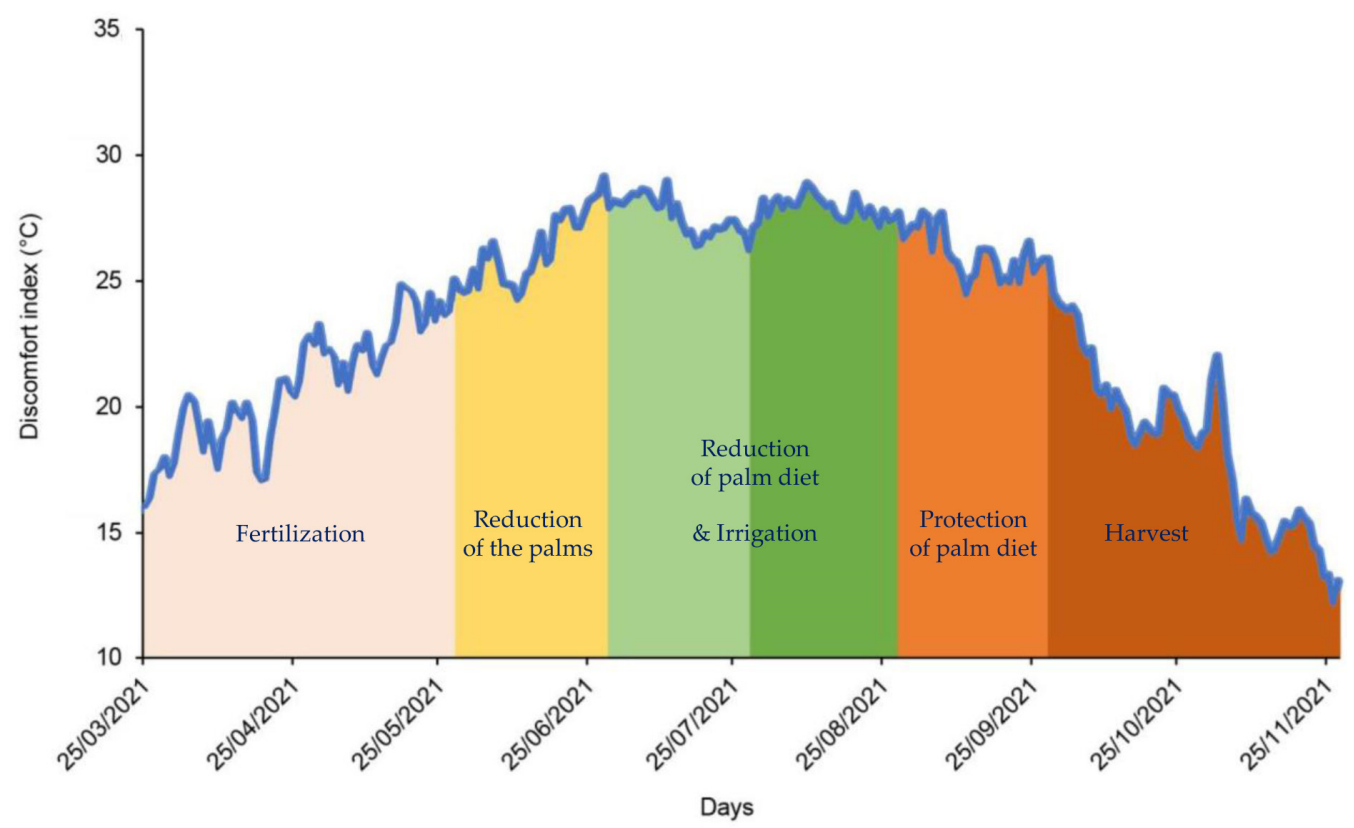

Figure 11. Human thermal stress fluctuations inside the palm grove during the phenological cycle of date palm.

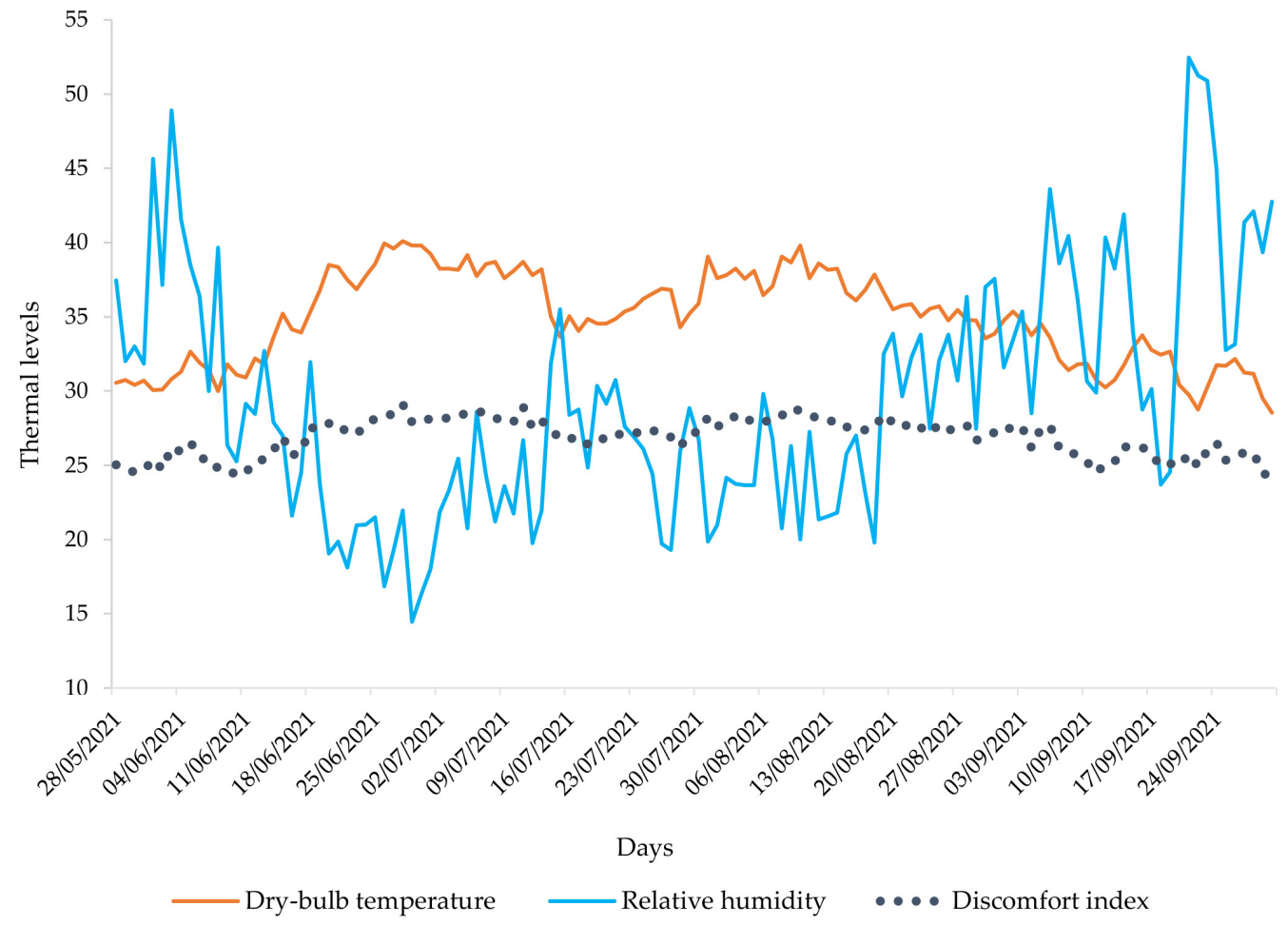

Figure 12. Daily averages of dry-bulb temperature $(\mathrm{Td})$, relative humidity $\left(\mathrm{R}_{\mathrm{H}}\right)$, and the discomfort index (DI) during the overheating period.

\section{Discussion}

In the following section, we discuss the major findings of the study and elaborate on its strength and limitations before elaborating on the implications of the study for practice and research.

For this study, we evaluated the human thermal stress levels inside a palm grove situated in the middle of an oasis settlement in Algeria during the phenological cycle 
of palm trees. The study aimed to assess the thermal requirements of the cultivators and the palm groves' owners during their tasks of date palm cultivation. Our research methodology combined mixed methods involving empirical (field measurements) and quantitative assessments of the outdoor thermal comfort. Despite the large number of studies carried out on the thermal requirements for palm tree growth and quality, none of the previous research has focused on the human outdoor thermal requirements during palm tree cultivation $[8-10,18,19]$. In addition, the palm grove area is considered as a crucial component of an oasis settlement in the arid regions, which can be liveable (houses) and usable (cultivated) at the same time [5,6].

With a wide-ranging and comprehensive approach, this research refers to the thermal requirements of rural oasis life on the edge of the desert, addressing the preservation of agricultural tradition and the impact of climate change.

\subsection{Findings and Recommendations}

To summarize the significant findings, we list the most important and tangible outcomes of our palm grove characterization as follows:

- During eight (8) months of the normal phenological cycle of palm trees, cultivators or inhabitants feel thermally discomfort for $70 \%$ of the total duration, equivalent to 168 days (more than five (5) months).

- Inhabitants, generally the owners of the palm trees, live inside the palm grove and are exposed to extreme thermal conditions, specifically to high day and night air temperatures during this period.

- The period between midday and 7:00 p.m. during June, July, and August was the hottest time when the air temperatures reached their maximum with $\mathrm{Td}_{\max }=46.3{ }^{\circ} \mathrm{C}$ and with the minimum relative humidity of $\mathrm{R}_{\mathrm{H} \min }=6.20 \%$ at 3:00 p.m. Remarkably, the cultivators avoid carrying out any tasks in that time due to the strong discomfort inside the palm grove area.

- Regular thermal requirements for this cultivar of date palm can adapt to air temperature ranges between zero and $50.4^{\circ} \mathrm{C}$ [16], unlike human thermal stress, which can be experienced from $25^{\circ} \mathrm{C}$. The Deglet Nour cultivar needs temperatures between $30{ }^{\circ} \mathrm{C}$ and $38^{\circ} \mathrm{C}$ for their peak fruit activity; these thresholds can generate a medium discomfort to extreme discomfort for human thermal sensitivity.

- Therefore, the average air temperature of no human discomfort is lower than the favourable air temperature thresholds of the suitable ranges for date palm activity. Temperatures under $25^{\circ} \mathrm{C}$ were only recorded during the beginning of the palm tree fertilization period and half of the harvest period.

- Unsurprisingly, relative humidity did not play a crucial thermal role in human discomfort levels, in contrast to date palm fruits, which can adapt to a range between $40 \%$ and $60 \%$ [20]. In such a climate, the outdoor thermal comfort was most influenced by air temperature.

\subsection{Strength and Limitations}

The strength of the current study relates to the empirical investigation of the human thermal requirements inside a productive palm grove of an oasis settlement. The context of the study combines the cultivated area, which includes a large number of palm trees (220) and a few other fruit trees, and the cultivators' house which is located in the middle of the palm grove. The study used field monitoring, which was carried out from March to November 2021 to cover the entire duration of the phenological cycle of the date palm.

The quantification of human outdoor thermal comfort fluctuations exclusively during the phenological stages of the palm grove provided insights into the thermal requirements of an oasis settlement and have bioclimatic design potential in the arid regions.

Our results can be compared with the studies of Boudjellal and Bourbia. [18], Rchid and Bencheikh [19], and Potchter et al. [10], studied the potential cooling effect inside an oasis settlement. No previous study has explored the human thermal issue throughout 
palm groves. Until now, there has been no single investigation of human outdoor thermal requirements in a cultivated palm grove based on hourly measurements during the phenological cycle of palm trees.

Our work aimed to identify the thermal requirements of the agriculture workers inside their fields in the Saharan territories in the medium term. The outcomes explored the human's response to microclimatic working conditions inside the palm groves, which can be adjusted to improve work quality and conditions. Furthermore, there is a need to rethink housing typologies and urban strategies throughout the palm grove areas of the oasis settlements.

Based on hourly, monthly and yearly thermal evaluations, accurate results could be obtained regarding the human thermal comfort associated with the palm grove's thermal requirements to ensure the housing settlements' resilience, preservation of the rural oasis culture, and sustainable land planning. The selected period was a typical period of date palm cultivation. Moreover, the selected months included the spring, summer and fall seasons, covering mild to extreme summer days. The measurement and results were based on the year 2021; longitudinal measurements and analyses may be carried out for a better understanding of comfort requirements during a more extended period.

Needless to say, we only chose to record two microclimatic parameters to assess human thermal comfort for almost eight (8) months. We should ideally have measured other parameters such as the wind speed and mean radiant temperature (Tmrt) to cover all the environmental parameters that are relevant to the outdoor thermal comfort assessments. Currently, we do not have devices to obtain wind speed, globe temperature, and surface temperature. We did our best to benefit from the recorded database and use it for understanding the human thermal requirements inside the palm grove. However, we had the advantage of taking measurements within a productive palm grove inside a liveable oasis settlement with the same morphological characteristics.

Another limitation is that we focused mainly on the microclimatic parameters to evaluate the outdoor thermal comfort and not on characterizing the human responses to the thermal fluctuations. The reliability of the outdoor thermal comfort assessments is related to both environmental conditions and individual characteristics. A qualitative approach needs to be taken with a large number of persons under similar conditions, as it was not possible in our study to gather all the cultivators at the same phenological stage. Future work should address surveys with many cultivators who are very familiar with palm groves in the territory. Therefore, future investigations should combine the quantitative and qualitative approaches.

\subsection{Implications for Practice and Research}

In summary, this study helped to identify the thermal requirements of humans during their tasks or outside their houses in the middle of a rural oasis settlement.

The implications of our work for practice may lead to a revision of the agricultural strategies in the oasis territories for date palm fruit production and the preservation of the palm tree heritage in these lands. Algeria counts more than 19 million palm trees of all varieties, including more than $62 \%$ of the Deglet Nour cultivar, with a date palm heritage area exceeding 13,000,000 ha. However, the government has not taken the chance to maintain oasis sustainability and to increase the capacity of date palm fruit production. The preservation of the relationship between people and the oasis settlement in Saharan lands starts basically with the improvement of the quality of life, especially under extreme weather conditions.

As a result, there is a lack of understanding and shared knowledge on palm grove cultivation and housing design practices throughout the oasis settlements. Our study can contribute to more significant initiatives and projects covering agricultural and urban planning policies for the Saharan lands by adapting the built environment to the cultivated areas and introducing recent technologies to help people with their daily living requirements, specifically in terms of energy consumption, mechanical tools and water management [3]. 
As a direct implication of our work, we advise countries in Africa and worldwide that cultivate palm trees to adapt their agricultural and urban policies in the concerned territories to people's requirements in terms of health, energy, and housing to preserve sustainability and strengthen the economic capital. On the other hand, we strongly recommend using Phoenix dactylifera only for agricultural reasons and not for shading strategies within neighbourhoods.

We believe that agronomists, architects, and urban planners can apply our findings to their solutions for devising people's thermal comfort requirements and for the conditions needed by date palm cultivars.

Therefore, we believe that the implementation of common solutions that adopt and use our findings and recommendations will enhance the impact of our study in the professional practice of bioclimatic urban planning [52,53]. Future research should investigate the outdoor thermal comfort at the city scale and develop urban-specific design recommendations [54].

\section{Conclusions}

In this study, the outdoor thermal comfort inside a palm grove during the phenological cycle was assessed based on eight (8) months of hourly measurement data (March to November 2021). Five principal phenological stages were examined: fertilization, reduction of the palms, reduction of palm dates, irrigation, protection of palm dates, and harvest. Furthermore, human thermal requirements were evaluated based on the discomfort index to specify the thermal stress of the workers and inhabitants during date palm development.

The study results indicated that in 5.5/8 months of the phenological cycle, the cultivators work under extreme thermal conditions. As expected in our hypothesis, the humidity was not a dominant climatic aspect in this period. Above the $25^{\circ} \mathrm{C}$, human discomfort increases, and humans become extremely uncomfortable when temperatures inside the palm grove reach $30{ }^{\circ} \mathrm{C}$ or slightly more.

Remarkably, all the laborious cultivation tasks such as reduction of the palms and dates, irrigation, and protection of the dates were almost all carried out during the hottest period (June, July, August, and September). On the other hand, liveability inside the palm groves represents a significant stress factor for the people for a long period of the year.

Although Phoenix dactylifera is a representative desert tree, it is not beneficial in terms of the cooling effect in the oasis settlements. Other trees or vegetations could have a more significant cooling effect (oasis effect) on the built environment in the oasis settlement. A high density of palm trees may generate a warming effect and push for an uncomfortable thermal environment.

Finally, the study provides several insights into the rural oasis characteristics. The results confirm the presence of a significant urban strategy gap between the adaptations of palm grove areas and the city.

Author Contributions: Conceptualization, M.E.M., S.A. and H.F.A.; methodology, M.E.M., S.A., M.F. and W.A.M.; formal analysis, M.E.M., S.A., H.F.A. and W.A.M.; investigation, M.E.M. and F.Z.B.R.; resources, M.E.M., S.A., H.F.A. and M.F.; data curation, M.E.M., S.A., W.A.M. and M.F.; writing—original draft preparation, M.E.M.; writing—review and editing, M.E.M., S.A., M.F. and W.A.M.; visualization, M.E.M. and F.Z.B.R.; supervision, S.A.; project administration, M.E.M., S.A. and H.F.A.; funding acquisition, S.A. All authors have read and agreed to the published version of the manuscript.

Funding: This research was funded by the Belgian Wallonia Brussels International (WBI), grant number SUB/2021/506217.

Institutional Review Board Statement: Not applicable.

Informed Consent Statement: Not applicable.

Data Availability Statement: The data presented in this article can be obtained from the corresponding author upon request. 


\begin{abstract}
Acknowledgments: This research was partly funded by the Belgian Wallonia Brussels International (WBI) and the Algerian Ministry of Higher Education and Scientific Research, which are gratefully acknowledged. This publication is part of the research project 2021-2022: Project: MIMOSA = MicroclIMate OasiS Algeria. We would like to acknowledge the LACOMOFA Laboratory, University of Biskra and the Sustainable Building Design (SBD) Laboratory at the University of Liege for the use of the monitoring equipment in this research and for valuable support during the experiments and data analysis. The authors would also like to thank the University of Biskra, Algeria, and the University of Liege, Belgium, for their assistance with administrative procedures.

Conflicts of Interest: The authors declare no conflict of interest. The funders had no role in the study's design; in the collection, in the analysis, or interpretation of data; in the writing of the manuscript; or in the decision to publish the results.
\end{abstract}

\title{
References
}

1. Munier, P. Le Palmier Dattier. Techniques Agricoles et Productions Tropicales; Maisonneuve et Larose: Paris, France, 1973 ; Volume 217.

2. Alkama, D.; Tacherift, A. Essai D'Analyse Typo-Morphologique des Noyaux Urbains Traditionnels Dans la Région des Ziban; Courrier du Savoir; University of Biskra: Biskra, Algeria, 2001.

3. Sarlak, M.; Ferretti, L.V.; Biasi, R. The Productive Landscape in the Desert Margin for the Sustainable Development of Rural Settlements: An Innovative Greenbelt for Maranjab Desert in Iran. Sustainability 2021, 13, 2077. [CrossRef]

4. born Bouzaher, S.L.; Alkama, D. The requalification of the palm trees of Ziban as a tool for sustainable planning. Procedia-Soc. Behav. Sci. 2013, 102, 508-519. [CrossRef]

5. Coté, M. (Ed.) La Ville et le Désert: Le Bas-Sahara Algérien; Karthala Éditions: Paris, France, 2005.

6. Côte, M. Signatures Sahariennes: Terroirs E Territoires Vus du Ciel; Méditerranée; Presses Universitaires de Provence: Aix-enProvence, France, 2012.

7. Taha, H.; Akbari, H.; Rosenfeld, A. Heat island and oasis effects of vegetative canopies: Micro-meteorological field-measurements. Theor. Appl. Climatol. 1991, 44, 123-138. [CrossRef]

8. Sellami, M.H.; Sifaoui, M.S. Measurements of microclimatic factors inside the oasis: Interception and sharing of solar radiation. Renew. Energy 1998, 13, 67-76. [CrossRef]

9. Saaroni, H.; Bitan, A.; Dor, E.B.; Feller, N. The mixed results concerning the 'oasis effect'in a rural settlement in the Negev Desert, Israel. J. Arid. Environ. 2004, 58, 235-248. [CrossRef]

10. Potchter, O.; Goldman, D.; Kadish, D.; Iluz, D. The oasis effect in an extremely hot and arid climate: The case of southern Israel. $J$ Arid. Environ. 2008, 72, 1721-1733. [CrossRef]

11. Amrani, K. L'oasis et la menace climatique: Aperçu et scénario probable. In Sesame: Sciences et Sociétés, Alimentation, Mondes Agricoles et Environnement; Mission Agrobiosciences-Inra: Grenoble, France, 2018.

12. Faci, M.; Oubadi, M.; Matari, A.; Farhi, Y. Analyse des journées caniculaires au sahara algérien. Rev. Régions Arid. 2018, 44, 37-42.

13. Van Schaik, C.P.; Terborgh, J.W.; Wright, S.J. The phenology of tropical forests: Adaptive significance and consequences for primary consumers. Annu. Rev. Ecol. Syst. 1993, 24, 353-377. [CrossRef]

14. Belguidoum, S. Urbanisation et urbanité au Sahara. In Méditerranée: Revue Géographique Des Pays Méditerranéens; Presses Universitaires de Provence: Aix-en-Provence, France, 2002; Volume 99, pp. 53-64.

15. FAOSTAT, 2019. Données 2017. Available online: https://www.fao.org/countryprofiles/index/fr/?iso3=DZA (accessed on 10 December 2021).

16. Faci, M.; Benziouche, S.E. Contribution to monitoring the influence of air temperature on some phenological stages of the date palm (cultivar 'Deglet Nour') in Biskra. J. Saudi Soc. Agric. Sci. 2021, 20, 248-256. [CrossRef]

17. Matallah, M.E.; Alkama, D.; Ahriz, A.; Attia, S. Assessment of the Outdoor Thermal Comfort in Oases Settlements. Atmosphere 2020, 11, 185. [CrossRef]

18. Boudjellal, L.; Bourbia, F. An evaluation of the cooling effect efficiency of the oasis structure in a Saharan town through remotely sensed data. Int. J. Environ. Stud. 2018, 75, 309-320. [CrossRef]

19. Rchid, A. The effects of green spaces (Palme trees) on the microclimate in arides zones, case study: Ghardaia, Algeria. Energy Procedia 2012, 18, 10-20.

20. Faci, M.; Benziouche, S.E. Relationship between Thermo-Hygrometric Variations and the Maturity of Dates in Biskra (Case of Deglet Nour); Tropicultura: Liège, Belgique, 2021.

21. Weather Spark. 2022. Available online: https:// weatherspark.com/ (accessed on 10 February 2022).

22. Matallah, M.E.; Alkama, D.; Teller, J.; Ahriz, A.; Attia, S. Quantification of the Outdoor Thermal Comfort within Different Oases Urban Fabrics. Sustainability 2021, 13, 3051. [CrossRef]

23. Benziouche, S.E. L'agriculture biologique, un outil de développement de la filière dattes dans la région des Ziban en Algérie. Cah. Agric. 2017, 26, 35008. [CrossRef]

24. Zaid, A.; De Wet, P.F. Chapter I Botanical and Systematic Description of Date Palm. In FAO Plant Production and Protection Papers; Food and Agriculture Organization of the United Nations: Roma, Italy, 1999; pp. 1-28.

25. Djerbi, M. Précis de Phoeniciculture; FAO: Rome, Italy, 1994; pp. 23-191. 
26. TESTO. TESTO 175 H1 Climate Measuring Instrument. Available online: https://static-int.testo.com/media/cf/01/1_8d8380280 / testo-480-Instruction-manual.pdf (accessed on 16 December 2021).

27. Labdaoui, K.; Mazouz, S.; Acidi, A.; Cools, M.; Moeinaddini, M.; Teller, J. Utilizing thermal comfort and walking facilities to propose a comfort walkability index (CWI) at the neighbourhood level. Build. Environ. 2021, 193, 107627. [CrossRef]

28. de Freitas, C.R.; Grigorieva, E.A. A comprehensive catalogue and classification of human thermal climate indices. Int. J. Biometeorol. 2015, 59, 109-120. [CrossRef]

29. Coccolo, S.; Kämpf, J.; Scartezzini, J.L.; Pearlmutter, D. Outdoor human comfort and thermal stress: A comprehensive review on models and standards. Urban Clim. 2016, 18, 33-57. [CrossRef]

30. Givoni, B. Estimation of the Effects of Climate on Man: Development of a New Thermal Index, Report to Unesco Building; Research Statistics; Hebrew University: Jerusalem, Israel, 1997.

31. Höppe, P. The physiological equivalent temperature-A universal index for the biometeorological assessment of the thermal environment. Int. J. Biometeorol. 1999, 43, 71-75. [CrossRef]

32. Fanger, P.O. Thermal comfort. In Analysis and Applications in Environmental Engineering; Danish Technical Press: Copenhagen, Denmark, 1970.

33. Staiger, H.; Laschewski, G.; Grätz, A. The perceived temperature-A versatile index for the assessment of the human thermal environment. Part A: Scientific basics. Int. J. Biometeorol. 2012, 56, 165-176. [CrossRef]

34. Fiala, D.; Havenith, G.; Bröde, P.; Kampmann, B.; Jendritzky, G. UTCI-Fiala multi-node model of human heat transfer and temperature regulation. Int. J. Biometeorol. 2012, 56, 429-441. [CrossRef]

35. Steadman, R.G. A universal scale of apparent temperature. J. Appl. Meteorol. Climatol. 1984, 23, 1674-1687. [CrossRef]

36. Thom, E.C. A New Concept for Cooling Degree-Days; US Weather Bureau: Washington, DC, USA, 1957.

37. Thom, E.C. The discomfort index. Weatherwise 1959, 12, 57-61. [CrossRef]

38. Moran, D.S.; Epstein, Y. Evaluation of the environmental stress index (ESI) for hot/dry and hot/wet climates. Ind. Health 2006, 44, 399-403. [CrossRef] [PubMed]

39. Gregorczuk, M.; Cena, K. Distribution of effective temperature over the surface of the earth. Int. J. Biometeorol. 1967, 11, 145-149. [CrossRef]

40. Belding, H.S.; Hatch, T.F. Index for evaluating heat stress in terms of resulting physiological strains. Heat. Pip. Air Cond. 1955, 27, 129-136.

41. Emmanuel, R. Thermal comfort implications of urbanization in a warm-humid city: The Colombo Metropolitan Region (CMR), Sri Lanka. Build. Environ. 2005, 40, 1591-1601. [CrossRef]

42. Nikolopoulou, M. Designing Open Spaces in the Urban Environment: A Bioclimatic Approach; EESD, FP5; Centre for Renewable Energy Sources: Athens, Greece, 2004.

43. Cheng, V.; Ng, E.; Chan, C.; Givoni, B. Outdoor thermal comfort study in a sub-tropical climate: A longitudinal study based in Hong Kong. Int. J. Biometeorol. 2012, 56, 43-56. [CrossRef]

44. Lai, D.; Guo, D.; Hou, Y.; Lin, C.; Chen, Q. Studies of outdoor thermal comfort in northern China. Build. Environ. 2014, 77, 110-118. [CrossRef]

45. Angouridakis, V.E.; Makrogiannis, T.J. The discomfort-index in Thessaloniki, Greece. Int. J. Biometeorol. 1982, 26, 53-59. [CrossRef]

46. Tselepidaki, I.; Santamouris, M.; Moustris, C.; Poulopoulou, G. Analysis of the summer discomfort index in Athens, Greece, for cooling purposes. Energy Build. 1992, 18, 51-56. [CrossRef]

47. Talukdar, M.S., Jr.; Hossen, M.S.; Baten, M.A. Trends of outdoor thermal discomfort in mymensingh: An application of Thoms' discomfort index. J. Environ. Sci. Nat. Resour. 2017, 10, 151-156. [CrossRef]

48. Khajoo, M.; Seyed Mustafa, T.S.; Fahiminejad, A.; Morsal, B. Determining Comfort Climate of Garmsar City for Development of Sport Tourism Using Olgyay's Method and Discomfort Index. Geography 2020, 10, 345-361.

49. Potchter, O.; Ben-Shalom, H.I. Urban warming and global warming: Combined effect on thermal discomfort in the desert city of Beer Sheva, Israel. J. Arid. Environ. 2013, 98, 113-122. [CrossRef]

50. Bady, M. Analysis of outdoor human thermal comfort within three major cities in Egypt. Open Access Libr. J. 2014, 1, e457. [CrossRef]

51. Ghani, S.; Bialy, E.M.; Bakochristou, F.; Gamaledin SM, A.; Rashwan, M.M.; Hughes, B. Thermal comfort investigation of an outdoor air-conditioned area in a hot and arid environment. Sci. Technol. Built Environ. 2017, 23, 1113-1131. [CrossRef]

52. Attia, S. Spatial and behavioral thermal adaptation in net zero energy buildings: An exploratory investigation. Sustainability 2020, 12, 7961. [CrossRef]

53. Widera, B. Comparative analysis of user comfort and thermal performance of six types of vernacular dwellings as the first step towards climate resilient, sustainable and bioclimatic architecture in western sub-Saharan Africa. Renew. Sustain. Energy Rev. 2021, 140, 110736. [CrossRef]

54. Madureira, H.; Andresen, T.; Monteiro, A. Green structure and planning evolution in Porto. Urban For. Urban Green. 2011, 10, 141-149. [CrossRef] 